\title{
Environmental biases in the study of ecological networks at the plan- etary scale
}

\author{
Timothée PoIsot \\ Université de Montréal — timothee.poisot@umontreal.ca \\ Gabriel BERGERON \\ Université de Sherbrooke — Gabriel. Bergeron3@uSherbrooke.ca \\ Kevin CAZELLES \\ University of Guelph — kcazelle@uoguelph.ca \\ Tad DALlas \\ Louisiana State University — tadallas@lsu . edu \\ Dominique GRAVEL \\ Université de Sherbrooke - Dominique.Gravel@uSherbrooke.ca \\ Andrew MACDONALD \\ Université de Montréal - andrew.macdonald@umontreal.ca \\ Benjamin MERCIER \\ Université de Sherbrooke - Benjamin.B.Mercier@USherbrooke.ca \\ Clément VioleT \\ Université de Sherbrooke - Clement.Violet@etudiant.univ-brest.fr \\ Steve VISSAULT \\ Université de Sherbrooke - Steve.Vissault@USherbrooke.ca
}

\begin{abstract}
Ecological networks are increasingly studied at large spatial scales, expanding their focus from a conceptual tool for community ecology into one that also adresses questions in biogeography and macroecology. This effort is supported by increased access to standardized information on ecological networks, in the form of openly accessible databases. Yet, there has been no systematic evaluation of the fitness for purpose of these data to explore synthesis questions at very large spatial scales. In particular, because the sampling of ecological networks is a difficult task, they are likely to not have a good representation of the diversity of Earth's bioclimatic conditions, likely to be spatially aggregated, and therefore unlikely to achieve broad representativeness. In this paper, we analyze over 1300 ecological networks in the mangal.io database, and discuss their coverage of biomes, and the geographic areas in which there is a deficit of data on ecological networks. Taken together, our results suggest that while some information about the global structure of ecological networks is available, it remains fragmented over space, with further differences by types of ecological interactions. This causes great concerns both for our ability to transfer knowledge from one region to the next, but also to forecast the structural change in networks under climate change.
\end{abstract}




\section{Introduction}

2 Ecological networks are a useful representation of ecological systems in which species or organisms interact (Heleno et al. 2014, Poisot \& Stouffer et al. 2016, Delmas et al. 2018), and there has been a recent explosion

4 of interest in their dynamics across large temporal scales (Tylianakis \& Morris 2017, Baiser et al. 2019), and along environmental gradients (Trøjelsgaard \& Olesen 2016, Pellissier et al. 2017). As ecosystems are changing

6 rapidly, networks are at risk of undergoing rapid and catastrophic changes to their structure: for example by invasion leading to a collapse (Strong \& Leroux 2014, Magrach et al. 2017), or by a "rewiring" of interactions 8 among existing species (Bartley et al. 2019, Guiden et al. 2019, Hui \& Richardson 2019). Simulation studies suggest that knowing the structure of the extant network, i.e. being able to map all interactions between species, is not sufficient (Thompson \& Gonzalez 2017) to predict the effects of external changes, and that data on the species, the local climate and its future projection, are also required.

This change in scope, from describing ecological networks as local, static objects, to dynamical ones that vary across space and time, has prompted several methodological efforts. First, tools to study spatial, temporal, and spatio-temporal variation of ecological networks in space and in relationship to environmental gradients have been developed and continuously expanded (Poisot et al. 2012, 2015, 2017). Second, there has been an improvement in large-scale data-collection, through increased adoption of molecular biology tools (Evans et al. 2016, Eitzinger et al. 2019, Makiola et al. 2019) and crowd-sourcing of data collection (Pocock et al. 2015, Bahlai \& Landis 2016, Roy et al. 2016). Finally, there has been a surge in the development of tools that allow us to infer species interactions (Morales-Castilla et al. 2015, Dallas et al. 2017) based on limited but complementary data on existing network properties (Stock et al. 2017), species traits (Gravel et al. 2013, Bartomeus et al. 2016, Brousseau et al. 2017, Desjardins-Proulx et al. 2017), and environmental conditions (Gravel et al. 2018). These latter approaches tend to perform well in data-poor environments (Beauchesne et al. 2016), and can be combined through ensemble modelling or model averaging to generate more robust predictions (Pomeranz et al. 2018). The task of inferring interactions is particularly important because ecological networks are difficult to adequately sample in nature (Banašek-Richter et al. 2004, Gibson et al. 2011, Chacoff et al. 2012, Jordano 2016). The common goal to these efforts is to facilitate the prediction of network structure, particularly over space (Poisot \& Gravel et al. 2016, Gravel et al. 2018, Albouy et al. 2019) and into the future (Albouy et al. 2014), in order to appraise the response of that structure to possible environmental changes. 
These disparate methodological efforts share another important trait: their continued success depends on state-

2 of-the art data management, but also on the availability of data that are representative to the area we pretend to model. Novel quantitative tools demand a higher volume of network data; novel collection techniques

4 demand powerful data repositories; novel inference tools demand easier integration between different types of data, including but not limited to: interactions, species traits, taxonomy, occurrences, and local bioclimatic

6 conditions. In short, advancing the science of ecological networks requires us not only to increase the volume of available data, but to pair these data with ecologically relevant metadata. Such data should also be made 8 available in a way that facilitates programmatic interaction so that they can be used by reproducible data analysis pipelines. Poisot \& Baiser et al. (2016) introduced mangal . io as a first step in this direction. In the years since the tool was originally published, we continued development of the data representation, amount and richness of metadata, and digitized and standardized as much ecological data as we could find. The second major release of this database contains over 1300 networks, 120000 interactions across close to 7000 taxa, and represents what is to our best knowledge the most complete collection of species interactions available.

Here we ask if the current mangal database is fit for the purpose of global-scale synthesis research into ecological networks. We conclude that interactions over most of the planet's surface are poorly described, despite an increasing amount of available data, due to temporal and spatial biases in data collection and digitization. In particular, Africa, South America, and most of Asia have very sparse coverage. This suggests that synthesis efforts on the worldwide structure or properties of ecological networks will be weaker within these areas. To improve this situation, we should digitize available network information and prioritize sampling towards data-poor locations.

\section{Global trends in ecological networks description}

\subsection{Network coverage is accelerating but spatially biased}

The earliest recorded ecological networks date back to the late nineteenth century, with a strong increase in the rate of collection around the 1980s (fig. 1). Although the volume of available networks has increased over time, the sampling of these networks in space has been uneven. In fig. 2, we show that globally, network collection is biased towards the Northern hemisphere, and than different types of interactions have been sampled in different places. As such, it is very difficult to find a spatial area of sufficiently large size in which we have 


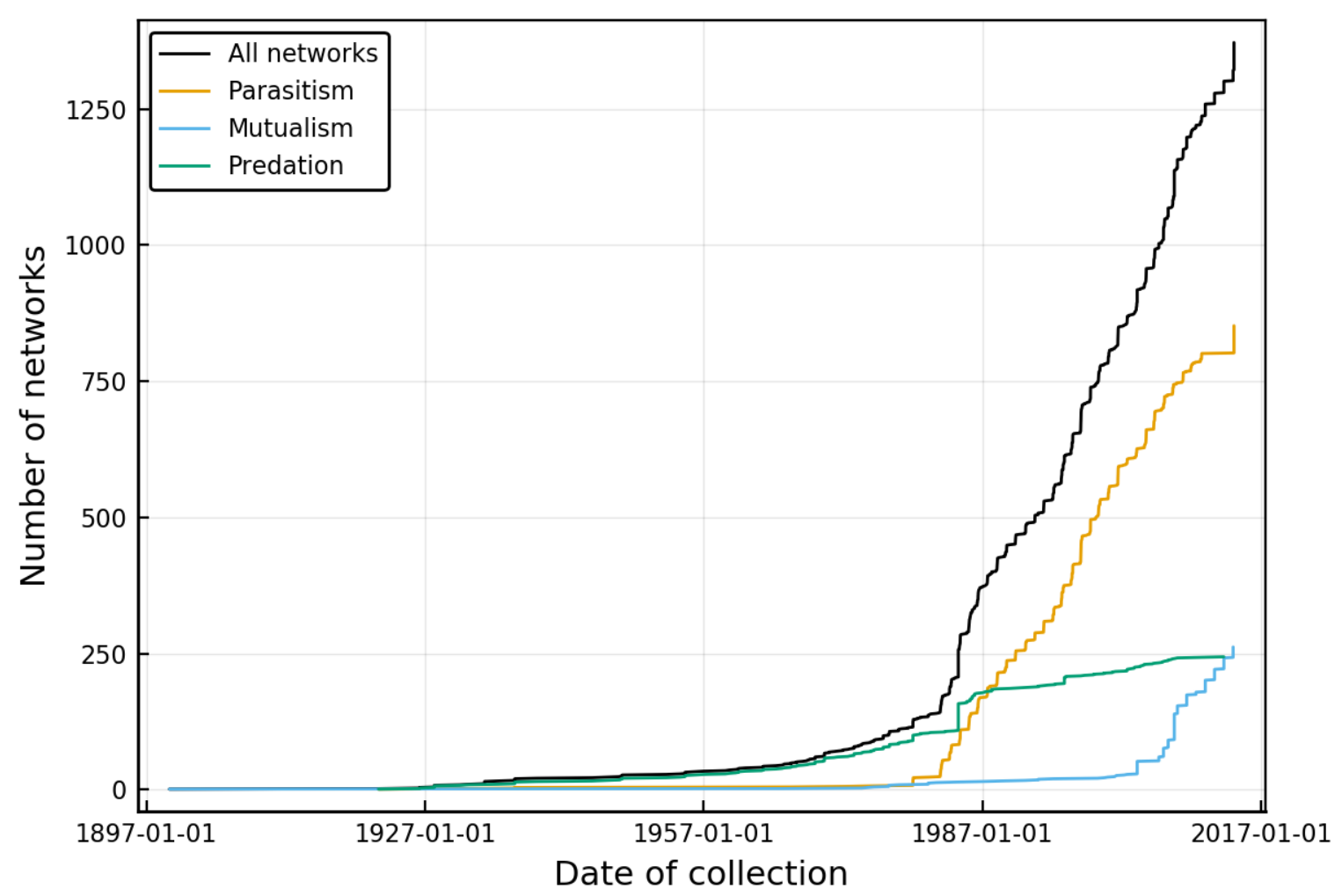

Figure 1: Cumulative number of ecological networks available in mangal.io as a function of the date of collection. About 1000 unique networks have been collected between 1987 and 2017, a rate of just over 30 networks a year. This temporal increase proceeds at different rates for diferent types of networks; while the description of food webs is more or less constant, the global acceleration in the dataset is due to increased interest in host-parasite interactions starting in the late 1970s, while mutualistic networks mostly started being recorded in the early 2000s. 


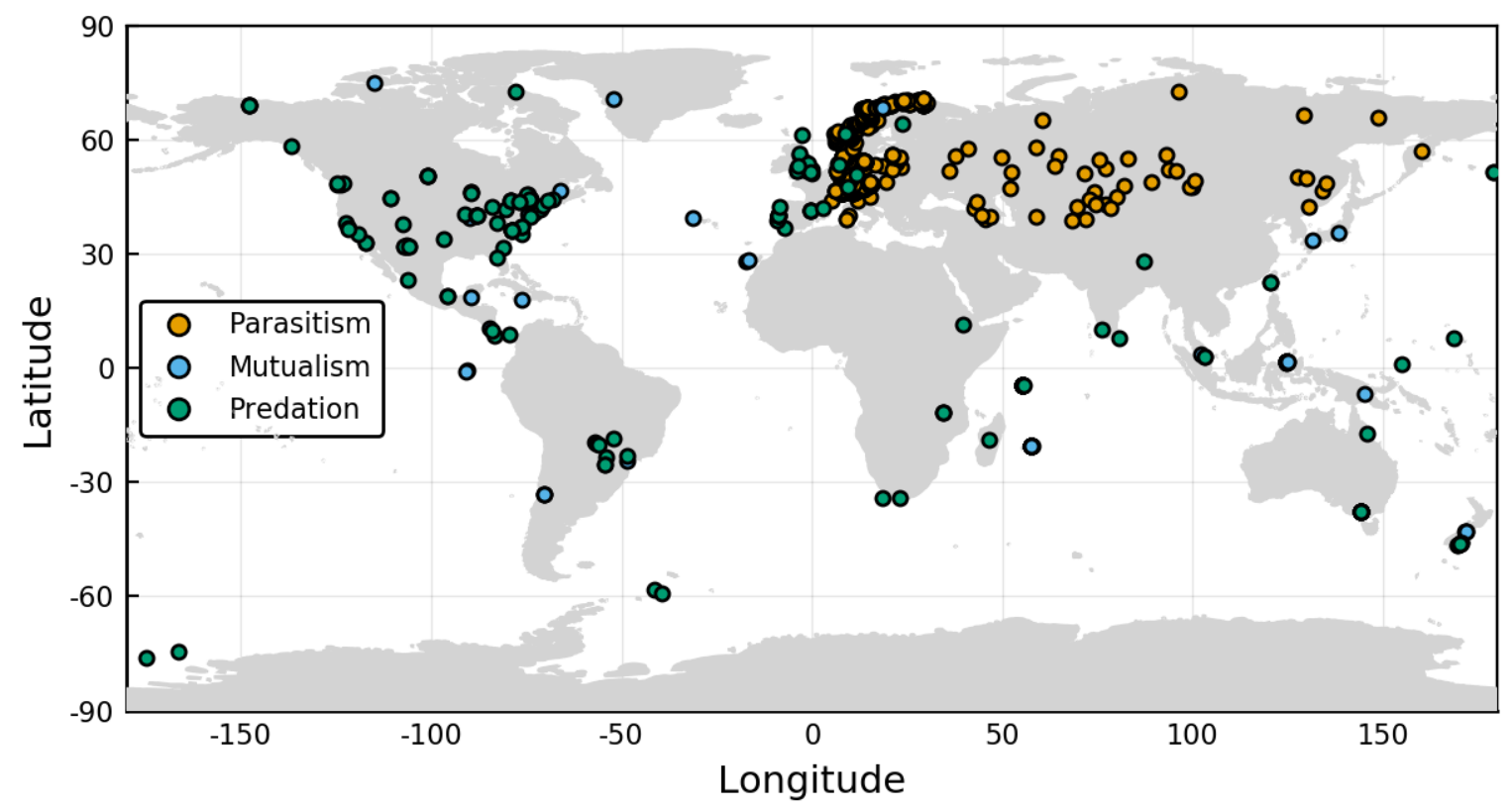

Figure 2: Each point on the map corresponds to a network with parasitic, mutualistic, and predatory interactions. It is noteworthy that the spatial coverage of these types of interactions is uneven; the Americas have almost no parasitic network, for example. Some places have barely been studied at all, including Africa and Eastern Asia. This concentration of networks around rich countries speaks to an inadequate coverage of the diversity of landscapes on Earth.

networks of predation, parasitism, and mutualism. The inter-tropical zone is particularly data-poor, either

2 because data producers from the global South correctly perceive massive re-use of their data by Western world scientists as a form of scientific neo-colonialism (as advanced by Mauthner \& Parry 2013), thereby providing

4 a powerful incentive against their publication, or because ecological networks are subject to the same data deficit that is affecting all fields on ecology in the tropics (Collen et al. 2008). As Bruna (2010) identified

6 almost ten years ago, improved data deposition requires an infrastructure to ensure they can be repurposed for future research, which we argue is provided by mangal . io for ecological interactions.

\subsection{Different interaction types have been studied in different biomes}

Whittaker (1962) suggested that natural communities can be partitioned across biomes, largely defined as a

function of their relative precipitation and temperature. For all networks for which the latitude and longitude was known, we extracted the value temperature (BioClim1, yearly average) and precipitation (BioClim12, 


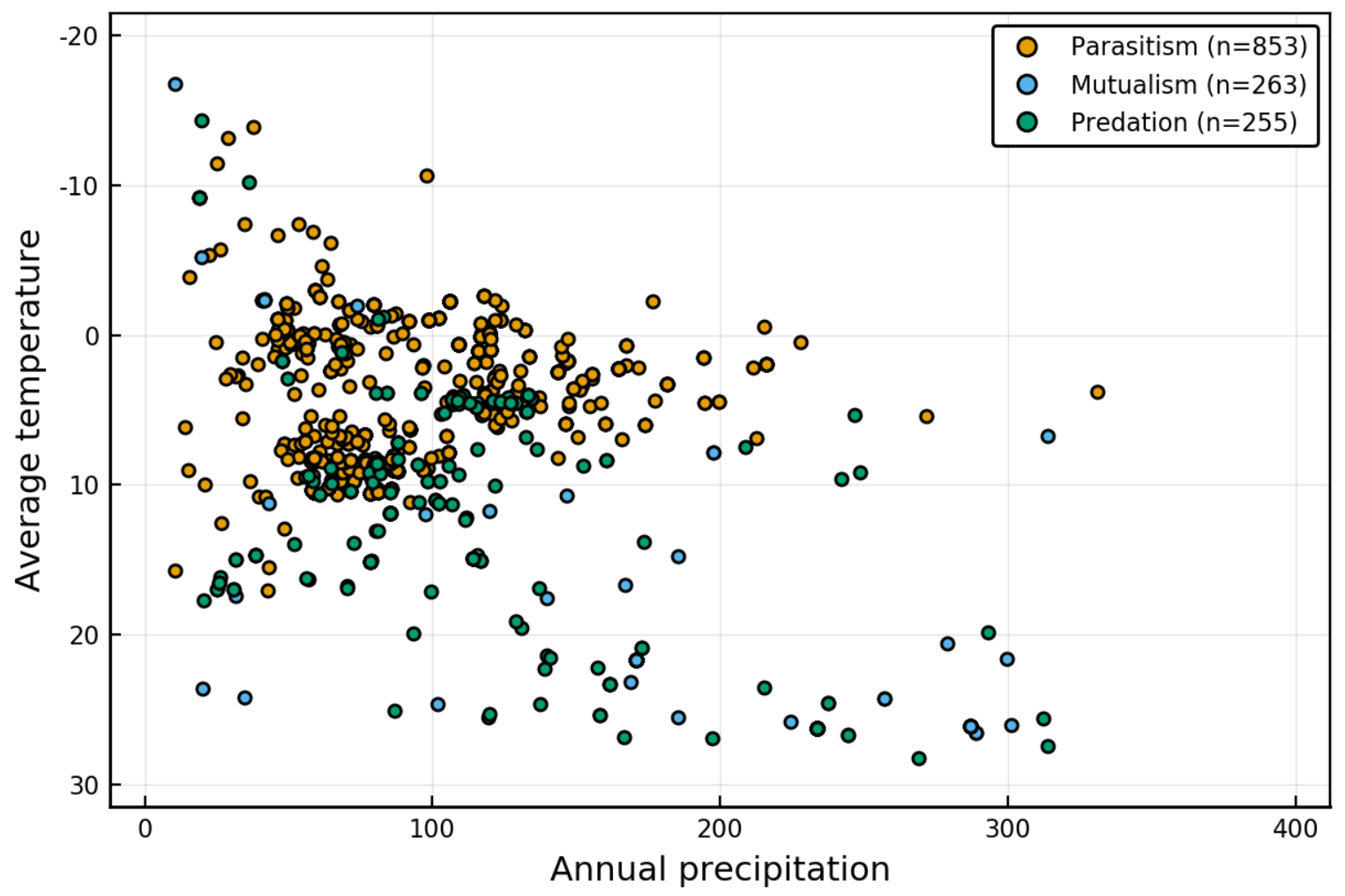

Figure 3: List of networks across in the space of biomes as originally presented by Whittaker (1962). Predation networks, i.e. food webs, seem to have the most global coverage; parasitism networks are restricted to low temperature and low precipitation biomes, congruent with the majority of them being in Western Europe.

total annual) from the WorldClim 2 data (Fick \& Hijmans 2017). Using these we can plot every network on the map of biomes drawn by Whittaker (1962) (note that because the frontiers between biomes are not based on any empirical or systematic process, they have been omitted from this analysis). In fig. 3, we show that even though networks capture the overall diversity of precipitation and temperature, types of networks have been studied in sub-spaces only. Specifically, parasitism networks have been studied in colder and drier climates; mutualism networks in wetter climates; predation networks display less of a bias.

Scaling up this analysis to the 19 BioClim variables in Fick \& Hijmans (2017), we extracted the position of every network in the bioclimatic space, conducted a principal component analysis on the scaled bioclimatic variables, and measured their distance to the centre of this space (0). This is a measurement of the "rarity" of the bioclimatic conditions in which any networks were sampled, with larger values indicating more unique combinations (the distance was ranged to $] 0 ; 1]$ for the sake of interpretation). As shown in fig. 4, mutualistic interactions tend to have values that are higher than both parasitism and predation, suggesting that they have been sampled in more unique environments. 


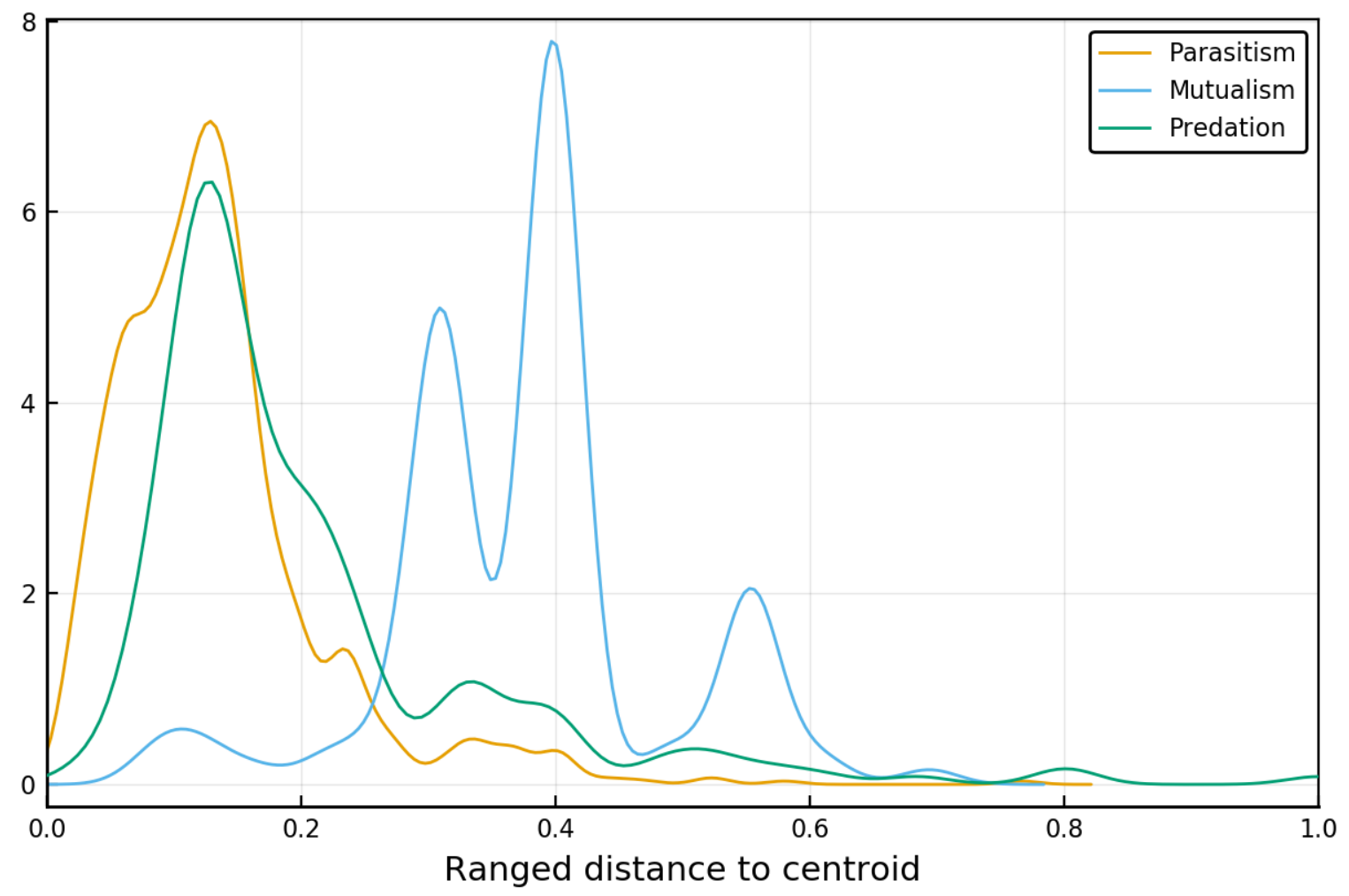

Figure 4: Distance to the centroid (in the scaled climatic space) for each network, as a function of the type of interaction. Larger values indicate that the network is far from its centroid, and therefore represents sampling in a more "unique" location. Mutualistic interactions have been, on average, studied in more diverse locations that parasitism or predatory networks. 


\subsection{Some locations on Earth have no climate analogue}

In figures 5, we represent the environmental distance between every pixel covered by BioClim data, and the three networks that were sampled in the closest environmental conditions (this amounts to a $k$ nearest neighbors with $k=3$ ). In short, higher distances correspond to pixels on Earth for which no climate analogue network exists, whereas the darker areas are well described. It should be noted that the three types of interIn short, it is not that we are systematically excluding some areas, but rather than some type of interactions 8 are more studied in specific environments. This shows how the lack of global coverage identified in fig. 3, for example, can cascade up to the global scale. These maps serve as an interesting measure of the extent to which spatial predictions can be trusted: any extrapolation of network structure in an area devoid of analogues should be taken with much greater caution than an extrapolation in an area with many similar networks.

\section{Conclusions}

\subsection{For what purpose are global ecological network data fit?}

What can we achieve with our current knowledge of ecological networks? The overview presented here shows a large and detailed dataset, compiled from almost every major biome on earth. It also displays our failure as a community to include some of the most threatened and valuable habitats in our work. Gaps in any dataset create uncertainty when making predictions or suggesting causal relationships. This uncertainty must be measured by users of these data, especially when predicting over the "gaps" in space or climate that we have identified. In this paper we are not making any explicit recommendations for synthesis workflows. Rather we argue that this needs to be a collective process, a collaboration between data collectors (who understand the deficiencies of these data) and data analysts (who understand the needs and assumptions of network methods).

One line of research that we feel can confidently be pursued lies in extrapolating the structure of ecological networks over gradients, not at the level of species and their interactions, but at that of the community. Mora et al. (2018) revealed that all food webs are more or less built upon the same structural backbone, which is in part due to strong evolutionary constraints on the establishment of species interactions (Dalla Riva \& Stouffer 2015); in other words, most networks are expected to be variations on a shared theme, and this facilitates 

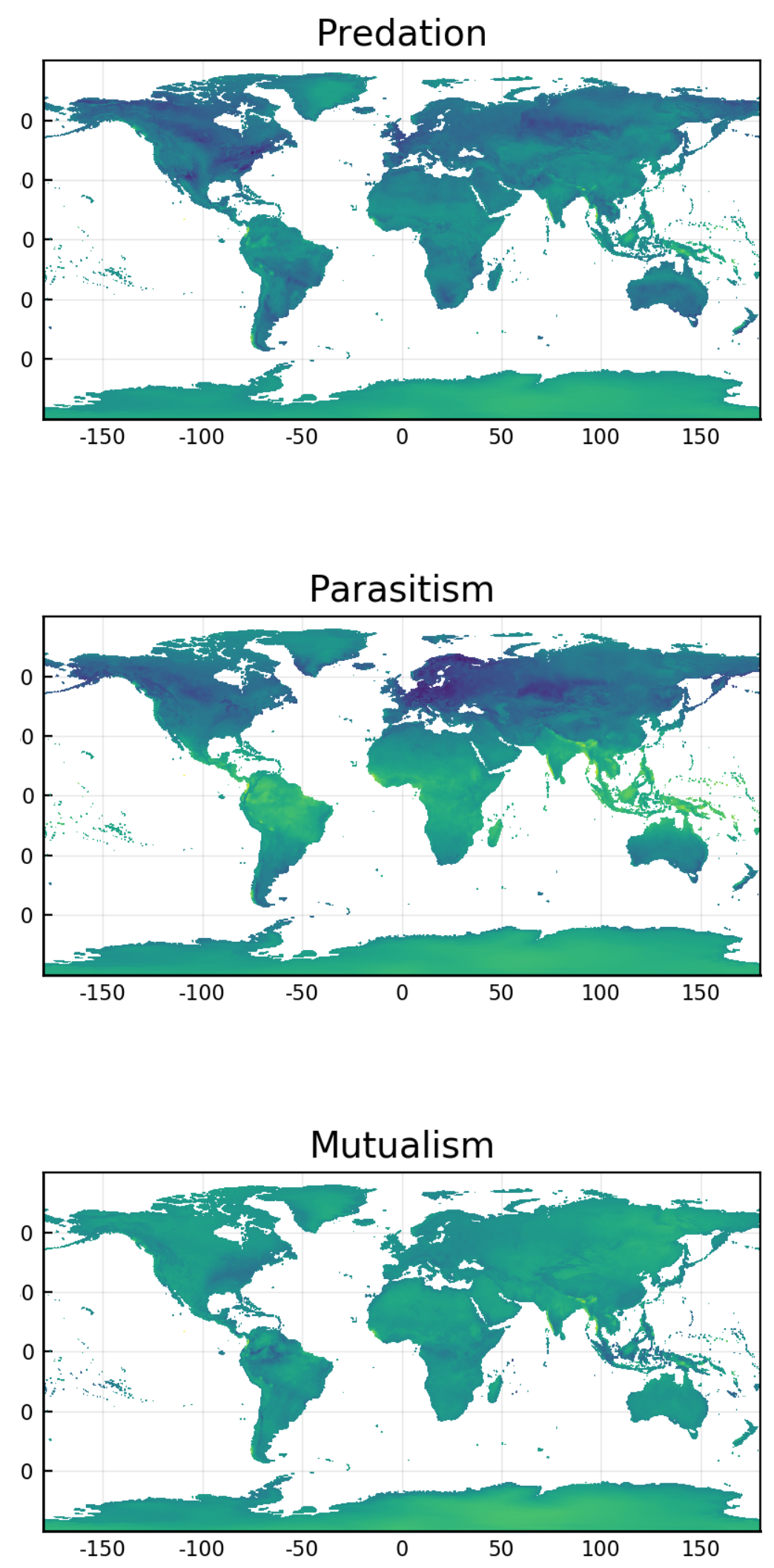

Figure 5: Environmental distance for every terrestrial pixel to its three closest networks. Areas of more yellow coloration are further away from any sampled network, and can therefore not be well predicted based on existing empirical data. Areas with a dark blue coloration have more analogues. The distance is expressed in arbitrary units and is relative. 
the task of predicting the overarching structure greatly. Finally, this approach to prediction which neglects the

composition of networks is justified by the fact that even in the presence of strong compositional turnover, network structure tends to be maintained at very large spatial scales (Dallas \& Poisot 2017).

\subsection{Can we predict the future of ecological networks under climate change?}

Perhaps unsurprisingly, most of our knowledge on ecological networks is derived from data that were collected after the 1990s (fig. 1). This means that we have worryingly little information on ecological networks before the acceleration of the climate crisis, and therefore lack a robust baseline. Dalsgaard et al. (2013) provide strong evidence that the extant shape of ecological networks emerged in part in response to historical trends in climate change. The lack of reference data before the acceleration of the effects of climate change is of particular concern, as we may be deriving intuitions on ecological network structure and assembly rules from networks that are in the midst of important ecological disturbances. Although there is some research on the response of co-occurrence and indirect interactions to climate change (Araújo et al. 2011, Losapio \& Schöb 2017), these are a far cry from actual direct interactions; similarly, the data on "paleo-foodwebs", i.e. from deep evolutionary time (Nenzén et al. 2014, Yeakel et al. 2014, Muscente et al. 2018) represent the effect of more progressive change, and may not adequately inform us about the future of ecological networks under severe climate change. However, though we lack baselines against which to measure the present, as a community we are in a position to provide one for the future. Climate change will continue to have important impacts on species distributions and interactions for at least the next century. The Mangal database provides a structure to organize and share network data, creating a baseline for future attempts to monitor and adapt to biodiversity change.

Possibly more concerning is the fact that the spatial distribution of sampled networks shows a clear bias towards the Western world, specifically Western Europe and the Atlantic coasts of the USA and Canada (fig. 2). This problem can be somewhat circumvented by working on networks sampled in places that are close analogues of those without direct information (almost all of Africa, most of South America, a large part of Asia). However, 5 suggests that this approach will rapidly be limited: the diversity of bioclimatic combinations on Earth leaves us with some areas lacking suitable analogues. These regions are expected to bear the worst of the socioeconomical (e.g. Indonesia) or ecological (e.g. polar regions) consequences of climate change. Cameron et al. (2019) reached a similar conclusion by focusing on food webs, and our analysis suggests that this 
worrying trend is in fact one that is shared by almost all types of interactions. All things considered, our current knowledge about the structure of ecological networks at the global scale leaves us under-prepared to predict their response to a warming world. From the limited available evidence, we can assume that ecosystem

4 services supported by species interactions will be disrupted (Giannini et al. 2017), in part because the mismatch between interacting species will increase (Damien \& Tougeron 2019) alongside the climatic debt accumulated 6 within interactions (Devictor et al. 2012).

\subsection{Active development and data contribution}

8

This is an open-source project: all data and all code supporting this manuscript are available on the Mangal project GitHub organization, and the figures presented in this manuscript are themselves packaged as a selfcontained analysis which can be run at any time. Our hope is that the success of this project will encourage similar efforts within other parts of the ecological community. In addition, we hope that this project will encourage the recognition of the contribution that software creators make to ecological research.

One possible avenue for synthesis work, including the contribution of new data to Mangal, is the use of these published data to supplement and extend existing ecological network data. This "semi-private" ecological synthesis could begin with new data collected by authors - for example, a host-parasite network of lake fish in Africa, or a pollination network of hummingbirds in Brazil. Authors could then extend their analyses by including a comparison to analogous data made public in Mangal. After publication of the research paper, the original data could themselves be uploaded to Mangal. This enables the reproducibility of this particular published paper. Even more powerfully, it allows us to build a future of dynamic ecological analyses, wherein analyses are automatically re-done as more data get added. This would allow a sort of continuous assessment of proposed ecological relationships in network structure. This cycle of data discovery and reuse is an example of the Data Life Cycle (Michener 2015) and represents one way to practice ecological synthesis.

Finally, it must be noted that as the amount of empirical evidence grows, so too should our understanding of existing relationships between network properties, networks properties and space, and the interpretation to be drawn from them. In this perspective, the idea of continuously updated analyses is very promising. Following the template laid out by White et al. (2019) and Yenni et al. (29-Jan-2019), it is feasible to update a series of canonical analyses any time the database grows, in order to produce living, automated synthesis of ecological networks knowledge. To this end, the mangal database has been integrated with EcologicalNetworks. jl 
(Poisot et al. 2019), which allows the development of flexible networks analysis pipelines. One immediate

2 target would be to borrow the methodology from Carlson et al. (2019), and provide estimate of the sampling effort required to accurately describe combinations of interaction types and bioclimatic conditions.

\section{Data and code availability:}

All code is available openly at https://github.com/PoisotLab/MangalSamplingStatus, and the data

6 can be retrieved from mangal. io and the BioClim database using the specified files. In addition, weekly updated pages presenting the analyses reported in this manuscript, including the data files, are available at https://poisotlab.github.io/MangalSamplingStatus/.

\section{References}

Albouy, C., P. Archambault, W. Appeltans, M. B. Araújo, D. Beauchesne, K. Cazelles, A. R. Cirtwill, M.J. Fortin, N. Galiana, S. J. Leroux, L. Pellissier, T. Poisot, D. B. Stouffer, S. A. Wood, and D. Gravel. 2019. The marine fish food web is globally connected. Nature Ecology \& Evolution 3: 1153-1161. Available at: https://doi.org/10.1038/s41559-019-0950-y.

Albouy, C., L. Velez, M. Coll, F. Colloca, F. L. Loc'H, D. Mouillot, and D. Gravel. 2014. From projected species distribution to food-web structure under climate change. Global Change Biology 20: 730-741. Available at: https://onlinelibrary.wiley.com/doi/abs/10.1111/gcb.12467 [Accessed July 17, 2019].

Araújo, M. B., A. Rozenfeld, C. Rahbek, and P. A. MArquet. 2011. Using species co-occurrence networks to assess the impacts of climate change. Ecography 34: 897-908.

BAHLAI, C. A., and D. A. LANDIS. 2016. Predicting plant attractiveness to pollinators with passive crowdsourcing. Royal Society Open Science 3: 150677. Available at: http://rsos.royalsocietypublishing.org/ content/3/6/150677 [Accessed October 18, 2016].

Baiser, B., D. Gravel, A. R. Cirtwill, J. A. Dunne, A. K. Fahimipour, L. J. Gilarranz, J. A. Grochow, D. Li, N. D. Martinez, A. McGrew, T. Poisot, T. N. Romanuk, D. B. Stouffer, L. B. Trotta, F. S. Valdovinos, R. J. Williams, S. A. Wood, and J. D. YeaKel. 2019. Ecogeographical rules and the macroecology of food 
10.1111/geb.12925 [Accessed May 21, 2019].

BAnAšEK-Richter, C., M.-F. CATtin, and L.-F. Bersier. 2004. Sampling effects and the robustness of quantitative and qualitative food-web descriptors. J. Theor. Biol. 226: 23-32.

Bartley, T. J., K. S. McCann, C. Bieg, K. Cazelles, M. Granados, M. M. Guzzo, A. S. MacDougall, T. D. Tunney, and B. C. McMeans. 2019. Food web rewiring in a changing world. Nat Ecol Evol 3: 345-354. 6 Available at: https://www . nature.com/articles/s41559-018-0772-3 [Accessed November 6, 2019].

Bartomeus, I., D. Gravel, J. M. Tylianakis, M. A. Aizen, I. A. Dickie, and M. Bernard-Verdier. 2016. A 8 common framework for identifying linkage rules across different types of interactions. Funct Ecol 30: 18941903. Available at: http://onlinelibrary.wiley.com/doi/10.1111/1365-2435.12666/abstract $10 \quad$ [Accessed September 2, 2016].

Beauchesne, D., Desjardins-ProulX, P. Archambault, and D. Gravel. 2016. Thinking Outside the Boxpredicting Biotic Interactions in Data-poor Environments. Vie et milieu-life and enVironment 66: 333-342.

Brousseau, P.-M., D. Gravel, and I. Tanya Handa. 2017. Trait-matching and phylogeny as predictors of predator-prey interactions involving ground beetles. Functional Ecology. Available at: http://doi .wiley . com/10.1111/1365-2435.12943 [Accessed July 28, 2017].

BrunA, E. M. 2010. Scientific Journals can Advance Tropical Biology and Conservation by Requiring Data Archiving. Biotropica 42: 399-401. Available at: http://onlinelibrary .wiley . com/doi/10.1111/j . 1744-7429.2010.00652.x/abstract [Accessed March 9, 2018].

Cameron, E. K., M. K. Sundqvist, S. A. Keith, P. J. Caradonna, E. A. Mousing, K. A. Nilsson, D. B. MetCAlfe, and A. T. Classen. 2019. Uneven global distribution of food web studies under climate change. Ecosphere 10: e02645. Available at: https://esajournals.onlinelibrary.wiley.com/doi/abs/10. 1002/ecs2 . 2645 [Accessed January 27, 2020].

Carlson, C. J., A. J. Phillips, T. A. Dallas, L. W. Alexander, and S. Bansal. 2019. What would it take to describe the global diversity of parasites? bioRxiv 815902. Available at: https://www.biorxiv.org/ content/10.1101/815902v1 [Accessed November 6, 2019]. sampling completeness in a desert plant-pollinator network. J. Anim. Ecol. 81: 190-200. 
Collen, B., M. Ram, T. Zamin, and L. McRae. 2008. The Tropical Biodiversity Data Gap: Addressing Disparity

2 in Global Monitoring. Tropical Conservation Science 1: 75-88. Available at: https://doi .org/10.1177/ 194008290800100202 [Accessed July 18, 2019].

4 Dalla Riva, G. V., and D. B. Stouffer. 2015. Exploring the evolutionary signature of food webs' backbones using functional traits. Oikos 125: 446-456.

Dallas, T., A. W. PARK, and J. M. DRAKE. 2017. Predicting cryptic links in host-parasite networks. PLOS Computational Biology 13: e1005557. Available at: http://journals.plos.org/ploscompbiol/article? id=10.1371/journal .pcbi. 1005557 [Accessed May 27, 2017].

DAllas, T., and T. POISOT. 2017. Compositional turnover in host and parasite communities does not change network structure. Ecography n/a-n/a. Available at: http://onlinelibrary.wiley.com/doi/10.1111/ ecog. 03514/abstract [Accessed December 11, 2017].

Dalsgaard, B., K. Trøjelsgaard, A. M. Martín González, D. Nogués-Bravo, J. Ollerton, T. Petanidou, B. Sandel, M. Schleuning, Z. Wang, C. Rahbek, W. J. Sutherland, J.-C. Svenning, and J. M. Olesen. 2013. Historical climate-change influences modularity and nestedness of pollination networks. Ecography 36 : $1331-1340$.

Damien, M., and K. Tougeron. 2019. Prey-predator phenological mismatch under climate change. Current Opinion in Insect Science. Available at: http://www. sciencedirect.com/science/article/pii/ S2214574518301895 [Accessed July 22, 2019].

Delmas, E., M. Besson, M.-H. Brice, L. A. Burkle, G. V. Dalla Riva, M.-J. Fortin, D. Gravel, P. R. Guimarẽes, D. H. Hembry, E. A. Newman, J. M. Olesen, M. M. Pires, J. D. Yeakel, and T. Poisot. 2018. Analysing ecological networks of species interactions. Biological Reviews 112540. Available at: http://doi.wiley. com/10.1111/brv. 12433 [Accessed June 20, 2018].

Desjardins-ProulX, P., I. Laigle, T. Poisot, and D. Gravel. 2017. Ecological interactions and the Netflix problem. PeerJ 5. Available at: https://doi .org/10.7717/peerj . 3644.

Devictor, V. ET AL. 2012. Differences in the climatic debts of birds and butterflies at a continental scale. [Accessed July 22, 2019]. 
Eitzinger, B., N. Abrego, D. Gravel, T. Huotari, E. J. Vesterinen, and T. Roslin. 2019. Assessing changes

2 in arthropod predator-prey interactions through DNA-based gut content analysis-variable environment, stable diet. Molecular Ecology 28: 266-280. Available at: https ://onlinelibrary.wiley.com/doi/abs/ $4 \quad 10.1111 / \mathrm{mec} .14872$ [Accessed July 19, 2019].

Evans, D. M., J. J. N. Kitson, D. H. Lunt, N. A. StraW, and M. J. O. Pocock. 2016. Merging DNA metabarcod6 ing and ecological network analysis to understand and build resilient terrestrial ecosystems. Functional Ecology. Available at: http://doi .wiley.com/10.1111/1365-2435.12659 [Accessed October 12, 2016].

8 FICK, S. E., and R. J. HiJmans. 2017. WorldClim 2: new 1-km spatial resolution climate surfaces for global land areas. Int. J. Climatol n/a-n/a. Available at: http://onlinelibrary.wiley.com/doi/10.1002/ joc.5086/abstract [Accessed May 19, 2017].

Giannini, T. C., W. F. Costa, G. D. Cordeiro, V. L. Imperatriz-Fonseca, A. M. SAraiva, J. Biesmeijer, and L. A. GARIBALDI. 2017. Projected climate change threatens pollinators and crop production in Brazil. PLOS ONE 12: e0182274. Available at: https://journals .plos.org/plosone/article?id=10.1371/journal . pone. 0182274 [Accessed July 19, 2019].

Gibson, R. H., B. Knott, T. Eberlein, and J. Memmott. 2011. Sampling method influences the structure of plant-pollinator networks. Oikos 120: 822-831. Available at: http://onlinelibrary.wiley.com/doi/ 10.1111/j.1600-0706.2010.18927.x/abstract [Accessed November 16, 2016].

Gravel, D., B. Baiser, J. A. Dunne, J.-P. Kopelke, N. D. Martinez, T. Nyman, T. Poisot, D. B. Stouffer, J. M. TYLIANAKIs, S. A. Wood, and T. Roslin. 2018. Bringing Elton and Grinnell together: a quantitative framework to represent the biogeography of ecological interaction networks. Ecography 0. Available at: https:// onlinelibrary.wiley.com/doi/abs/10.1111/ecog.04006 [Accessed October 4, 2018].

Gravel, D., T. Poisot, C. Albouy, L. Velez, and D. Mouillot. 2013. Inferring food web structure from predator-prey body size relationships R. Freckleton (Ed.). Methods in Ecology and Evolution 4: 1083-1090. Available at: http://doi.wiley.com/10.1111/2041-210X.12103 [Accessed October 12, 2016].

Guiden, P. W., S. L. Bartel, N. W. Byer, A. A. Shipley, and J. L. Orrock. 2019. Predator-Prey Interactions in the Anthropocene: Reconciling Multiple Aspects of Novelty. Trends in Ecology \& Evolution 0. Available at: https://www . cell .com/trends/ecology-evolution/abstract/S0169-5347(19)30064-3 [Accessed March 22, 2019]. 
Heleno, R., C. Garcia, P. Jordano, A. Traveset, J. M. Gómez, N. Blüthgen, J. Memmott, M. Moora, J. Cerdeira, S. Rodríguez-Echeverría, H. Freitas, and J. M. Olesen. 2014. Ecological networks: delving into the architecture of biodiversity. Biol Lett 10. Available at: http://www.ncbi.nlm.nih.gov/pmc/ articles/PMC3917341/ [Accessed July 16, 2017].

6 Hui, C., and D. M. Richardson. 2019. How to Invade an Ecological Network. Trends in Ecology \& Evolution 34: 121-131. Available at: http://www.sciencedirect.com/science/article/pii/S016953471830274X $8 \quad$ [Accessed March 21, 2019].

JordANO, P. 2016. Chasing Ecological Interactions. PLOS Biol 14: e1002559. Available at: http: //journals . plos.org/plosbiology/article?id=10.1371/journal .pbio.1002559 [Accessed September 27, 2016 ].

LOSAPIO, G., and C. SсHÖв. 2017. Resistance of plant-plant networks to biodiversity loss and secondary extinctions following simulated environmental changes. Functional Ecology 31: 1145-1152. Available at: https: //bes journals . onlinelibrary.wiley.com/doi/abs/10.1111/1365-2435.12839 [Accessed July 19, 2019].

Magrach, A., A. Holzschuh, I. Bartomeus, V. Riedinger, S. P. Roberts, M. Rundlöf, A. Vujić, J. B. Wickens, V. J. Wickens, R. Bommarco, J. P. González-Varo, S. G. Potts, H. G. Smith, I. Steffan-Dewenter, and M. VILÀ. 2017. Plant-pollinator networks in semi-natural grasslands are resistant to the loss of pollinators during blooming of mass-flowering crops. Ecography n/a-n/a. Available at: http://onlinelibrary . wiley.com/doi/10.1111/ecog.02847/abstract [Accessed February 27, 2017].

Makiola, A. Et AL. 2019. Key questions for next-generation biomonitoring. Front. Environ. Sci. 7. Available at: https://www .frontiersin .org/articles/10.3389/fenvs .2019.00197/abstract [Accessed December 5, 2019].

Mauthner, N. S., and O. Parry. 2013. Open Access Digital Data Sharing: Principles, Policies and Practices. Social Epistemology 27: 47-67. Available at: https ://doi .org/10.1080/02691728.2012 .760663 [Accessed July 18, 2019].

MicheneR, W. K. 2015. Ten Simple Rules for Creating a Good Data Management Plan. PLOS Comput Biol 11: e1004525. Available at: http://journals.plos.org/ploscompbiol/article?id=10.1371/journal. pcbi. 1004525 [Accessed October 27, 2016]. 
Mora, B. B., D. Gravel, L. J. Gilarranz, T. Poisot, and D. B. Stouffer. 2018. Identifying a common backbone of interactions underlying food webs from different ecosystems. Nature Communications 9: 2603.

4 Available at: https://www .nature.com/articles/s41467-018-05056-0 [Accessed July 4, 2018 ].

Morales-Castilla, I., M. G. Matias, D. Gravel, and M. B. Araújo. 2015. Inferring biotic interactions from proxies. Trends in Ecology \& Evolution.

Muscente, A. D., A. Prabhu, H. Zhong, A. Eleish, M. B. Meyer, P. Fox, R. M. Hazen, and A. H. Knoll. 8 2018. Quantifying ecological impacts of mass extinctions with network analysis of fossil communities. PNAS 201719976. Available at: http://www .pnas .org/content/early/2018/04/18/1719976115 [Accessed June 12, 2018].

NenzÉn, H. K., D. Montoya, and S. VArela. 2014. The Impact of 850,000 Years of Climate Changes on the Structure and Dynamics of Mammal Food Webs. PLOS ONE 9: e106651. Available at: https://journals . plos.org/plosone/article?id=10.1371/journal . pone.0106651 [Accessed July 19, 2019].

Pellissier, L., C. Albouy, J. Bascompte, N. Farwig, C. Graham, M. Loreau, M. A. Maglianesi, C. J. Melián, C. Pitteloud, T. Roslin, R. Rohr, S. SaAvedra, W. Thuiller, G. Woodward, N. E. Zimmermann, and D. GRAVEL. 2017. Comparing species interaction networks along environmental gradients. Biol Rev Camb Philos Soc.

Pocock, M. J. O., H. E. Roy, C. D. Preston, and D. B. Roy. 2015. The Biological Records Centre: a pioneer of citizen science. Biol J Linn Soc 115: 475-493. Available at: https ://academic.oup.com/biolinnean/ article/115/3/475/2440508 [Accessed July 19, 2019].

Poisot, T., B. Baiser, J. A. Dunne, S. Kéfi, F. Massol, N. Mouquet, T. N. Romanuk, D. B. Stouffer, S. A. WoOD, and D. GRAVEL. 2016. mangal - making ecological network analysis simple. Ecography 39: 384-390. Available at: http://doi.wiley.com/10.1111/ecog.00976 [Accessed January 20, 2017].

Poisot, T., Z. Belisle, L. Hoebeke, M. Stock, and P. Szefer. 2019. EcologicalNetworks.jl - analysing ecological networks. Ecography.

Poisot, T., E. Canard, D. Mouillot, N. Mouquet, and D. Gravel. 2012. The dissimilarity of species interaction networks. Ecol. Lett. 15: 1353-1361. Available at: http://onlinelibrary.wiley.com/doi/10. 1111/ele.12002/full [Accessed September 2, 2016]. 
2 Poisot, T., D. Gravel, S. Leroux, S. A. Wood, M.-J. Fortin, B. Baiser, A. R. Cirtwill, M. B. Araújo, and D. B. Stouffer. 2016. Synthetic datasets and community tools for the rapid testing of ecological hypotheses. Ecography 39: 402-408. Available at: http://onlinelibrary.wiley.com/doi/10.1111/ecog. 01941/abstract [Accessed September 2, 2016].

Poisot, T., C. Gueveneux-Julien, M.-J. Fortin, D. Gravel, and P. Legendre. 2017. Hosts, parasites and their interactions respond to different climatic variables. Global Ecol Biogeogr n/a-n/a.

8 Poisot, T., D. B. Stouffer, and D. Gravel. 2015. Beyond species: why ecological interaction networks vary through space and time. Oikos 124: 243-251. Available at: http://onlinelibrary.wiley.com/doi/ 10.1111/oik.01719/full.

Poisot, T., D. B. StOuffer, and S. Kéfi. 2016. Describe, understand and predict: why do we need networks in ecology? Funct Ecol 30: 1878-1882. Available at: http://onlinelibrary.wiley.com/doi/10.1111/ 1365-2435.12799/abstract [Accessed January 9, 2017].

PomeranZ, J. P., R. M. Thompson, T. Poisot, and J. S. HARding. 2018. Inferring predator-prey interactions in food webs. Methods in Ecology and Evolution 0. Available at: https://bes journals . onlinelibrary. wiley.com/doi/abs/10.1111/2041-210X.13125 [Accessed November 19, 2018].

Roy, H. E., E. Baxter, A. SAunders, and M. J. O. Pocock. 2016. Focal Plant Observations as a Standardised Method for Pollinator Monitoring: Opportunities and Limitations for Mass Participation Citizen Science. PLOS ONE 11: e0150794. Available at: https://journals.plos .org/plosone/article?id=10. 1371/journal pone.0150794 [Accessed July 19, 2019].

Stock, M., T. Poisot, W. Waegeman, and B. D. Baets. 2017. Linear filtering reveals false negatives in species interaction data. Scientific Reports 7: 45908. Available at: http://www . nature.com/srep/2017/ 170406/srep45908/full/srep45908.html [Accessed April 24, 2017].

Strong, J. S., and S. J. Leroux. 2014. Impact of Non-Native Terrestrial Mammals on the Structure of the Terrestrial Mammal Food Web of Newfoundland, Canada. PLOS ONE 9: e106264. Available at: http:// journals.plos.org/plosone/article?id=10.1371/journal . pone. 0106264 [Accessed February 15, 2017].

Thompson, P. L., and A. GonZALEz. 2017. Dispersal governs the reorganization of ecological networks under 
environmental change. Nature Ecology \& Evolution 1: 0162. Available at: http://www.nature.com/ articles/s41559-017-0162 [Accessed May 9, 2017].

4 TRøjelsgaARD, K., and J. M. Olesen. 2016. Ecological networks in motion: micro- and macroscopic variability across scales. Funct Ecol 30: 1926-1935. Available at: http://onlinelibrary .wiley . com/doi/10.

6 1111/1365-2435.12710/abstract [Accessed September 1, 2016].

TYliAnAKis, J. M., and R. J. MorRis. 2017. Ecological Networks Across Environmental Gradients. An8 nual Review of Ecology, Evolution, and Systematics 48: 25-48. Available at: https://doi .org/10.1146/ annurev-ecolsys-110316-022821 [Accessed November 30, 2017].

White, E. P., G. M. Yenni, S. D. TAYlor, E. M. Christensen, E. K. Bledsoe, J. L. Simonis, and S. K. M. Ernest. 2019. Developing an automated iterative near-term forecasting system for an ecological study. Methods in Ecology and Evolution 10: 332-344. Available at: https://bes journals.onlinelibrary.wiley .com/ doi/abs/10.1111/2041-210X.13104 [Accessed October 29, 2019].

Whittaker, R. H. 1962. Classification of Natural Communities. Botanical Review 28: 1-239. Available at: https://www . jstor .org/stable/4353649 [Accessed July 12, 2019].

Yeakel, J. D., M. M. Pires, L. Rudolf, N. J. Dominy, P. L. Koch, P. R. Guimarães, and T. Gross. 2014. Collapse of an ecological network in Ancient Egypt. PNAS 111: 14472-14477. Yenni, G. M., E. M. Christensen, E. K. Bledsoe, S. R. Supp, R. M. Diaz, E. P. White, and S. K. M. Ernest. 29Jan-2019. Developing a modern data workflow for regularly updated data. PLOS Biology 17: e3000125. Available at: https://journals .plos .org/plosbiology/article?id=10.1371/journal.pbio. 3000125 [Accessed October 29, 2019]. 